\title{
Limitations of wind extraction from 4D-Var assimilation of ozone
}

\author{
D. R. Allen ${ }^{1}$, K. W. Hoppel ${ }^{1}$, G. E. Nedoluha ${ }^{1}$, D. D. Kuhl ${ }^{1}$, N. L. Baker ${ }^{2}$, L. Xu ${ }^{2}$, and T. E. Rosmond ${ }^{3}$ \\ ${ }^{1}$ Remote Sensing Division, Naval Research Laboratory, Washington, DC, USA \\ ${ }^{2}$ Marine Meteorology Division, Naval Research Laboratory, Monterey, CA, USA \\ ${ }^{3}$ Science Applications International Corporation, Forks, WA, USA
}

Correspondence to: D. R. Allen (douglas.allen@nrl.navy.mil), K. W. Hoppel (karl.hoppel@nrl.navy.mil)

Received: 19 October 2012 - Published in Atmos. Chem. Phys. Discuss.: 19 December 2012

Revised: 8 March 2013 - Accepted: 11 March 2013 - Published: 27 March 2013

\begin{abstract}
Time-dependent variational data assimilation allows the possibility of extracting wind information from observations of ozone or other trace gases. Since trace gas observations are not available at sufficient resolution for deriving feature-track winds, they must be combined with model background information to produce an analysis. If done with time-dependent variational assimilation, wind information may be extracted via the adjoint of the linearized tracer continuity equation. This paper presents idealized experiments that illustrate the mechanics of tracer-wind extraction and demonstrate some of the limitations of this procedure. We first examine tracer-wind extraction using a simple onedimensional advection equation. The analytic solution for a single trace gas observation is discussed along with numerical solutions for multiple observations. The limitations of tracer-wind extraction are then explored using highly idealized ozone experiments performed with a development version of the Navy Global Environmental Model (NAVGEM) in which globally distributed hourly stratospheric ozone profiles are assimilated in a single $6 \mathrm{~h}$ update cycle in January 2009. Starting with perfect background ozone conditions, but imperfect dynamical conditions, ozone errors develop over the $6 \mathrm{~h}$ background window. Wind increments are introduced in the analysis in order to reduce the differences between background ozone and ozone observations. For "perfect" observations (unbiased and no random error), this results in root-mean-square (RMS) vector wind error reductions of up to $\sim 4 \mathrm{~m} \mathrm{~s}^{-1}$ in the winter hemisphere and tropics. Wind extraction is more difficult in the summer hemisphere due to weak ozone gradients and smaller background wind errors. The limitations of wind extraction are also explored for observations with imposed random errors and for limited sampling patterns. As expected, the amount
\end{abstract}

of wind information extracted degrades as observation errors or data voids increase. In the case of poorly specified observation error covariances, assimilation of ozone data with imposed errors may result in increased RMS wind error, since the assimilation is constrained too tightly to the noisy observations.

\section{Introduction}

One of the major deficiencies of the current global observing system is inadequate global wind profile information (WMO, 2000). Upper air wind observations from pilot reports, radiosondes, and cloud and water vapor feature tracking leave large gaps, particularly in the tropics, Southern Ocean, and in most of the stratosphere and mesosphere. In the extratropics, traditional mass-wind balance provides some constraint on the wind, but this balance fails in the tropics and for subsynoptic scales (less than $\sim 1000 \mathrm{~km}$ ) in the extratropics. Even with improved tropical balance approximations the need for wind observations is crucial (Žagar et al., 2008). Spaceborne Doppler wind lidar (DWL) has the potential to provide wind profile measurements in the troposphere and lower stratosphere, but it is extremely expensive (National Research Council, 2007). The only currently planned DWL mission, the Atmospheric Dynamics Mission (ADM-Aeolus) (Stoffelen et al., 2005), will be limited to a single line-ofsight wind component, altitudes below $\sim 26 \mathrm{~km}$, and simple along-track sampling. Future DWLs may improve sampling and data quality, but they are unlikely to ever provide wind information above about $30 \mathrm{~km}$. Extracting wind information from trace gas observations is an attractive prospect, particularly in the stratosphere, where satellite measurements of 
ozone, water vapor, and nitrous oxide are available. Current trace gas (tracer) observations are not generally available at the spatial and temporal resolutions necessary to derive feature-track wind vectors. For example, limb-viewing observations from polar-orbiting satellites such as the Aura Microwave Limb Sounder (MLS) (Waters et al., 1999) or the Michelson Interferometer for Passive Atmospheric Sounding (MIPAS) (Fisher et al., 2008) provide good vertical resolution, but lack the horizontal coverage to identify and track individual features, while total column ozone measurements from the Ozone Monitoring Instrument (OMI) (Levelt et al., 2006) and the Ozone Mapper Profiler Suite (OMPS) nadir mapper (Flynn et al., 2009) provide excellent horizontal coverage, but lack necessary vertical profile information. Data assimilation algorithms, on the other hand, have the potential to extract wind information indirectly from limited tracer observations. For example, Andersson et al. (1994) showed that analyzed wind fields may be influenced by the 4D-Var assimilation of TIROS (Television Infrared Observation Satellite) Operational Vertical Sounder (TOVS) radiance channels sensitive to water vapor, providing the first illustration that dynamical information may be extracted by assimilation of tracer information.

The theoretical basis for this work was first examined using idealized tracer observations, simple 1-D and 2-D transport equations, and an extended Kalman filter (Daley, 1995, 1996). Daley showed that wind extraction is possible with observations that are sufficiently dense, frequent, and accurate. Wind extraction becomes difficult when the observation frequency decreases, when model errors become large (such as damping, errors in phase speed, or violating stability limits), or when the true constituent time tendency is small relative to the observation errors. The latter occurs when there are small gradients in the tracer field, when the winds are weak, or when the winds are blowing parallel to the tracer contours. In general, if the amplitude of the constituent structure is smaller than the observation error, it is not possible to extract wind information.

The results from Daley $(1995,1996)$ provide promise that wind extraction from tracers is possible in idealistic 1-D and 2-D settings. The next step is to apply these concepts to more realistic experiments. Riishøjgaard (1996) applied 4D-Var assimilation techniques to a $2-\mathrm{D}$ barotropic vorticity equation model and simulated ozone observations based on realistic flow conditions at the $200 \mathrm{hPa}$ pressure level. Using perfect ozone data with complete global coverage and starting with a purely zonal flow field, Riishøjgaard (1996) was able to extract a substantial amount of wind information at all latitudes, although the impact on the meridional wind was weaker in the tropics. Using a series of experiments with different model resolutions, frequency of observations, and assimilation time windows, it was shown that the best results were for cases where tracer features were displaced a few grid points between successive observations. If the displacements are approximately one grid point or less, the advection is too weak, whereas if the displacements are over many grid points, the small perturbation approximation of the tangent linear model breaks down. In either case, wind extraction is made more difficult, and there is the possibility that assimilating tracer data may even make the winds worse, rather than better. A detailed understanding of the limitations of these processes is therefore necessary for optimal assimilation of tracer data.

A study using realistic sampling of total column ozone and a full numerical weather prediction (NWP) forecast model was performed by Peuch et al. (2000). They examined windtracer coupling by assimilating simulated TOVS total column ozone measurements with a 4D-Var assimilation system for a $12 \mathrm{~h}$ period. Two polar-orbiting satellites were simulated, providing global coverage every six hours. When using perfect observations, reductions of zonal and meridional wind errors occurred throughout the extratropical troposphere and lower stratosphere of both hemispheres and in the tropical stratosphere, with error reductions peaking at $\sim 2-3 \mathrm{~m} \mathrm{~s}^{-1}$ in the upper troposphere for each wind component. Since changes in the total column ozone are caused by horizontal and vertical advection, primarily in the upper troposphere and lower stratosphere, and by changes in tropopause height, it is expected that wind improvements should maximize in the upper troposphere. A series of experiments in which Gaussian noise was added to the data revealed that a noise standard deviation of $2 \%$ or less is necessary for positive impact on the global wind field. Another experiment showed that adding a bias of $1 \%$ to the total column ozone data results in an overall degradation as well. These results indicate that wind extraction (at least in the case of total column ozone assimilation) requires highly precise and unbiased observations.

Given these results it is not surprising that when Peuch et al. (2000) attempted to assimilate real TOVS total column ozone data, the wind analyses were degraded. Similarly, Han and McNally (2010) reported that solar-backscatter ultra violet (SBUV) ozone assimilation could degrade the operational European Centre for Medium-Range Weather Forecasts (ECMWF) 4D-Var wind analyses. In order to prevent erroneous wind increments, they stated that "the observation operator that links wind adjustments to changes in ozone concentration has been artificially cut." More promising results were obtained by Semane et al. (2009) using the MétéoFrance 4D-Var system Action de Recherche Petite Echelle Grande Echelle (ARPEGE) coupled to an offline chemistry transport model, Modèle de Chimie Atmosphérique à Grande Echelle (MOCAGE). They compared results from 3-monthlong (23 January-22 April 2006) data assimilation experiments performed with and without use of Aura MLS ozone profiles. A very slight reduction $\left(<0.1 \mathrm{~m} \mathrm{~s}^{-1}\right)$ in the global wind bias (relative to radiosondes) was found in the lower stratosphere when MLS data were included, but there was apparently no reduction in the standard deviations. Error variance reduction diagnostics were also used to show that MLS 
ozone observations reduce the global initial background error variance of the horizontal divergence and relative vorticity fields. Although these results are promising, the research grade MLS retrievals used in this study are not available in near-real time. It is unclear at this point whether tracer observations from current satellites are of sufficient accuracy and frequency to benefit wind analyses in an operational setting; a potential source of operational ozone profiles is the OMPS on the NASA Suomi National Polar-orbiting Partnership (NPP) mission (Flynn et al., 2009), launched 28 October 2011. In addition, ozone-sensitive infrared radiances can potentially provide dynamical information via tracer-wind coupling in NWP systems (Dragani and McNally, 2013).

In this study we will examine some of the limitations of wind extraction from ozone assimilation. To accomplish this we first provide a simple illustration of tracer-wind extraction in 4D-Var, without the use of initial background covariances between the tracer and the meteorological fields, by solving the cost function minimization for assimilation of tracer observations using a discrete formulation of the problem in one spatial dimension (Sect. 2). Theoretical discussions of cost function minimization provided in Riishøjgaard (1996) and Peuch et al. (2000) using continuous functions are very helpful to understand how the wind field can be influenced by tracer observations, but these discussions do not provide practical understanding of the discrete problem. By examining the analytic solution to the discrete problem we gain insight into the relative roles of various factors in facilitating/inhibiting wind extraction. We then present idealized experiments using a 4-D system in order to examine the limitations of wind extraction in a more realistic setting (Sect. 3). These experiments use the NRL Atmospheric Variational Data Assimilation System-Accelerated Representer (NAVDAS-AR) 4D-Var assimilation system (Xu et al., 2005; Rosmond and $\mathrm{Xu}, 2006$ ) with a preoperational version of the Navy Global Environmental Model (NAVGEM) semiLagrangian forecast model to assimilate idealized global ozone profiles in the stratosphere ( $\sim 4000$ profiles per hour evenly sampled over the globe), with and without imposed errors. With these experiments we are able to examine the limitations of wind extraction due to geophysical conditions as well as due to observation errors and sampling patterns. The overall goal of this paper is to help bridge the gap between theoretical studies of tracer assimilation and full NWP tests using real data that have seen marginal or no wind improvement. Sections 4 and 5 provide a summary and conclusions, respectively.

\section{Illustration of wind extraction using a 1-D model}

This section illustrates the process of wind extraction from tracer observations using a simple 1-D model with timedependent variational assimilation.

\subsection{Derivation of the 1-D model solution}

The nonlinear forward model $M$ is based on the 1-D advection equation for a passive tracer embedded in a constant wind field. The system of equations is as follows, with dependent variables $q$ (tracer mixing ratio) and $u$ (wind), and independent variables $\lambda$ (horizontal position) and $t$ (time).

$\frac{\partial q}{\partial t}+u \frac{\partial q}{\partial \lambda}=0$
$\frac{\partial u}{\partial t}=0$

The problem is to determine the model initial state ( $q$ and $u$ at $t=0$ ) that produces a forecast that best matches any incoming observations over the assimilation window. The 4D-Var approach requires a linear approximation to the forecast equations, often called the tangent linear model (TLM). The TLM is constructed by linearizing the full model about the time-varying background state (identified by subscript $b$ ) and considering small perturbations (identified by primes) relative to the background. The TLM (Eq. 2) describes the evolution of the perturbation terms (also called "increments") over the analysis time window.

$$
\begin{aligned}
& \frac{\partial q^{\prime}}{\partial t}+u_{\mathrm{b}} \frac{\partial q^{\prime}}{\partial \lambda}+u^{\prime} \frac{\partial q_{\mathrm{b}}}{\partial \lambda}=0 \\
& \frac{\partial u^{\prime}}{\partial t}=0
\end{aligned}
$$

Equation (2) shows that the perturbation mixing ratio changes with time both by advection of the tracer perturbations by the background wind and by advection of the spatially varying background tracer field by the wind perturbations.

The model is discretized using a periodic three grid point domain, as illustrated in Fig. 1. The wind is constant in space and time, but that value can be incremented in the assimilation algorithm. The model state vector is defined by $\boldsymbol{x}=\left(x_{1}, x_{2}, x_{3}, x_{4}\right)=\left(q_{1}, q_{2}, q_{3}, u\right)$, where $q_{1}, q_{2}$, and $q_{3}$ indicate tracer mixing ratios at the three grid points, and $u$ is the spatially invariant wind. The finite difference formulation uses first-order Euler forward time stepping and secondorder central differencing for the spatial derivatives. This choice of discretization is made for simplicity rather than accuracy, as it is known to be unstable (Rood, 1987). However, since we are only taking one time step, instability is not a problem. The discretized TLM is written in matrix form below, using the nondimensional wind $U=u \Delta t / \Delta \lambda$, where $\Delta t$ is the time step and $\Delta \lambda$ is the grid spacing. $\mathbf{M}_{t_{n-1} \rightarrow t_{n}}$ is a matrix that performs one forward time step of the linearized version of the nonlinear forward model $M$ (given in Eq. 1), and $t_{n}=t_{n-1}+\Delta t$ is the time corresponding to time step $n$. 

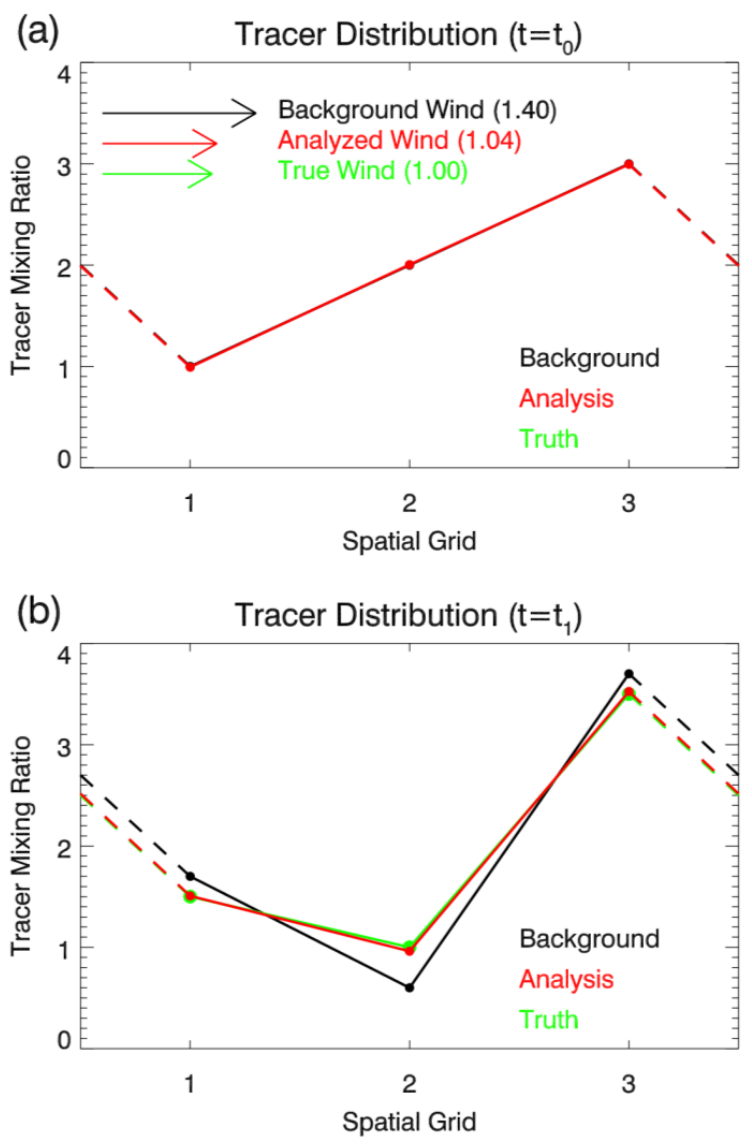

Fig. 1. The analytic solution to the cost function minimization problem for one observation at grid cell 1 and at the final time $t_{1}$. Tracer mixing ratio is shown for the (a) initial and (b) final times. Background is in black, analysis is in red, and truth is in green. Dashed lines are used to indicate the periodic boundary conditions. Arrows indicate the strength of the background wind, analyzed wind, and true wind, as labeled.

$$
\begin{aligned}
& \left(\begin{array}{c}
x_{1}^{\prime}\left(t_{n}\right) \\
x_{2}^{\prime}\left(t_{n}\right) \\
x_{3}^{\prime}\left(t_{n}\right) \\
x_{4}^{\prime}\left(t_{n}\right)
\end{array}\right)=\mathbf{M}_{t_{n-1} \rightarrow t_{n}}\left(\begin{array}{c}
x_{1}^{\prime}\left(t_{n-1}\right) \\
x_{2}^{\prime}\left(t_{n-1}\right) \\
x_{3}^{\prime}\left(t_{n-1}\right) \\
x_{4}^{\prime}\left(t_{n-1}\right)
\end{array}\right) \\
= & \left(\begin{array}{cccc}
1 & -\frac{U_{\mathrm{b}}}{2} & \frac{U_{\mathrm{b}}}{2} & \left(\frac{x_{3 \mathrm{~b}}\left(t_{n-1}\right)-x_{2 \mathrm{~b}}\left(t_{n-1}\right)}{2}\right) \\
\frac{U_{\mathrm{b}}}{2} & 1 & -\frac{U_{\mathrm{b}}}{2} & \left.\frac{x_{1 b}\left(t_{n-1}\right)-x_{3 \mathrm{~b}}\left(t_{n-1}\right)}{2}\right) \\
-\frac{U_{\mathrm{b}}}{2} & \frac{U_{\mathrm{b}}}{2} & 1 & \left(\frac{x_{2 \mathrm{~b}}\left(t_{n-1}\right)-x_{1 b}\left(t_{n-1}\right)}{2}\right) \\
0 & 0 & 0 & 1
\end{array}\right)\left(\begin{array}{c}
x_{1}^{\prime}\left(t_{n-1}\right) \\
x_{2}^{\prime}\left(t_{n-1}\right) \\
x_{3}^{\prime}\left(t_{n-1}\right) \\
x_{4}^{\prime}\left(t_{n-1}\right)
\end{array}\right)
\end{aligned}
$$

To make the problem amenable to analytic solution, the chosen assimilation window is a single time step with tracer observations (no wind observations) only at the final time $t_{1}$. Note that if tracer observations occur at the initial time $t_{0}$, they cannot impact the wind analysis via the TLM because no advection has yet occurred (discussed further below). We define a quadratic cost function that depends on the difference between the observed and forecast value of the observations and on the difference between the initial analyzed state and the initial background state. Model errors are not included in the cost function (i.e., a "perfect model" assumption). The cost function $J$ can then be written

$$
\begin{aligned}
J & =J_{0}^{\mathrm{b}}+J^{r} \\
& =\frac{1}{2}\left[\boldsymbol{x}\left(t_{0}\right)-\boldsymbol{x}_{\mathrm{b}}\left(t_{0}\right)\right]^{T} B^{-1}\left[\boldsymbol{x}\left(t_{0}\right)-\boldsymbol{x}_{\mathrm{b}}\left(t_{0}\right)\right] \\
& +\frac{1}{2}\left[H\left(\boldsymbol{x}\left(t_{1}\right)\right)-\boldsymbol{y}\left(t_{1}\right)\right]^{T} R^{-1}\left[H\left(\boldsymbol{x}\left(t_{1}\right)\right)-\boldsymbol{y}\left(t_{1}\right)\right] .
\end{aligned}
$$

Here $J_{0}^{\mathrm{b}}$ is the scalar cost function for the background forecast error at the beginning of the time period $\left(t=t_{0}\right)$ and $J^{r}$ is the scalar cost function for the observation error. Observations are indicated by the vector $\boldsymbol{y}\left(t_{1}\right)$. The TLM is implicitly included in the cost function via the calculation of the state vector after one time step, $\boldsymbol{x}\left(t_{1}\right)=\mathbf{M}_{t_{0} \rightarrow t_{1}} \boldsymbol{x}\left(t_{0}\right)$. This operation provides the time-dependent component that distinguishes the cost function from a standard 3D-Var formulation. The background and observation error covariance matrices, $B$ and $R$, are specified to be diagonal, with background error standard deviation of the tracer $(q)$ and wind ( $u$ ) denoted by $\sigma_{q}$ and $\sigma_{u}$, respectively, and the tracer observation error standard deviation denoted by $\sigma_{\mathrm{ob}}$. Note that the error standard deviations for each variable must be specified as nonzero, since the cost function becomes singular and no solution to the variational problem as formulated will exist in the case of zero standard deviation.

In general, the background error covariance could include specified wind-tracer correlations. This would provide another mechanism for linking winds and tracers in the cost function in addition to the TLM (Holm et al., 1999). In our experiments, the wind-tracer interaction is all contained in the TLM matrix $\mathbf{M}$. If there were also observations at the initial time, the additional term to the cost function would not contain the $\mathbf{M}$ matrix because no advection is required to relate $t=t_{0}$ observations to the initial state. In general, tracer observations that occur near the end of the assimilation time window will have the greatest potential to influence the wind analysis because they correspond to longer advection times. In the full 4D-Var system, the greater impact of the observations that occur later in the assimilation window will be mostly due to the following two factors. First, the quality of the background decreases with time, making the observations near the end of the window more valuable. Second, the background error covariance evolves over the time window from initial decorrelation between tracer and wind, to a correlated (flow-dependent) covariance, which results in better use of later observations.

The observation operator $H$ (which may be nonlinear) maps the model state vector onto the observations. The observations will be specified as the tracer mixing ratio at grid points (i.e., $H=(1,0,0,0)$ for a single observation at $\left.\lambda_{1}\right)$. The cost function for a single observation at grid point 1 , as 
a function of initial perturbations, becomes

$$
\begin{aligned}
& \boldsymbol{J}\left(\boldsymbol{x}^{\prime}\left(t_{0}\right)\right)=J_{0}^{\mathrm{b}}\left(\boldsymbol{x}^{\prime}\left(t_{0}\right)\right)+J^{r}\left(\boldsymbol{x}^{\prime}\left(t_{0}\right)\right) \\
= & \frac{1}{2}\left[\frac{\left(x_{1}^{\prime}\left(t_{0}\right)\right)^{2}}{\sigma_{q}^{2}}+\frac{\left(x_{2}^{\prime}\left(t_{0}\right)\right)^{2}}{\sigma_{q}^{2}}+\frac{\left(x_{3}^{\prime}\left(t_{0}\right)\right)^{2}}{\sigma_{q}^{2}}+\frac{\left(x_{4}^{\prime}\left(t_{0}\right)\right)^{2}}{\sigma_{u}^{2}}\right] \\
+ & \frac{1}{2}\left[\frac{\left(H\left(\mathbf{M}_{t_{0} \rightarrow t_{1}} \boldsymbol{x}^{\prime}\left(t_{0}\right)\right)-\varepsilon\right)^{2}}{\sigma_{\mathrm{ob}}^{2}}\right] .
\end{aligned}
$$

The innovation (also referred to as the observation minus forecast departures, or $\mathrm{OmF}) \varepsilon=y-x_{1 b}\left(t_{1}\right)$ depends only on the background and observation, so remains fixed in the cost function. The analysis solution is the initial state that minimizes the cost function, i.e., $\partial J / \partial \boldsymbol{x}^{\prime}\left(t_{0}\right)=0$. In general, the gradient of the cost function with respect to each initial state variable can be calculated using the chain rule:

$$
\frac{\partial J}{\partial x_{j}^{\prime}\left(t_{0}\right)}=\frac{\partial J_{0}^{\mathrm{b}}}{\partial x_{j}^{\prime}\left(t_{0}\right)}+\sum_{k} \frac{\partial J^{r}}{\partial x_{k}^{\prime}\left(t_{1}\right)} \frac{\partial x_{k}^{\prime}\left(t_{1}\right)}{\partial x_{j}^{\prime}\left(t_{0}\right)}=0 .
$$

The Jacobian $\partial x_{k}^{\prime}\left(t_{1}\right) / \partial x_{j}^{\prime}\left(t_{0}\right)$ can be recognized as the transpose of the elements of the TLM matrix (Eq. 3), also called the adjoint (see Errico (1997) for a discussion of adjoint models). The adjoint model propagates sensitivity of the cost function with respect to the state vector backwards in time from $t_{1}$ to $t_{0}$. Note that in our simple model the indices $j$ and $k$ vary from 1 to 4 . We will now examine solutions to the cost function minimization problem, both for a single observation (Sect. 2.2) and for multiple observations (Sect. 2.3).

\subsection{Solutions for a single observation}

For the case of a single observation at grid point 1 and time $t_{1}$, the gradient of the cost function can be directly evaluated and the resulting linear equations solved analytically. Defining $\Gamma=\left(x_{2 \mathrm{~b}}\left(t_{0}\right)-x_{3 \mathrm{~b}}\left(t_{0}\right)\right) / 2$ as the initial background tracer gradient at $\lambda_{1}$, the solution is

$$
\begin{aligned}
& q_{1}^{\prime}\left(t_{0}\right)=\left\{\frac{\sigma_{\mathrm{ob}}^{2}}{\sigma_{q}^{2}}+\left(1+\frac{U_{\mathrm{b}}^{2}}{2}\right)+\Gamma^{2} \frac{\sigma_{u}^{2}}{\sigma_{q}^{2}}\right\}^{-1} \varepsilon \\
& q_{2}^{\prime}\left(t_{0}\right)=\left\{\frac{\sigma_{\mathrm{ob}}^{2}}{\sigma_{q}^{2}}+\left(1+\frac{U_{\mathrm{b}}^{2}}{2}\right)+\Gamma^{2} \frac{\sigma_{u}^{2}}{\sigma_{q}^{2}}\right\}^{-1}\left(-\frac{U_{\mathrm{b}}}{2}\right) \varepsilon \\
& q_{3}^{\prime}\left(t_{0}\right)=\left\{\frac{\sigma_{\mathrm{ob}}^{2}}{\sigma_{q}^{2}}+\left(1+\frac{U_{\mathrm{b}}^{2}}{2}\right)+\Gamma^{2} \frac{\sigma_{u}^{2}}{\sigma_{q}^{2}}\right\}^{-1}\left(\frac{U_{\mathrm{b}}}{2}\right) \varepsilon \\
& u^{\prime}\left(t_{0}\right)=\left\{\frac{\sigma_{\mathrm{ob}}^{2}}{\sigma_{u}}+\left(1+\frac{U_{\mathrm{b}}^{2}}{2}\right) \frac{\sigma_{q}^{2}}{\sigma_{u}^{2}}+\Gamma^{2}\right\}^{-1}(-\Gamma) \varepsilon .
\end{aligned}
$$

We briefly discuss several general properties of this solution that will extend to the realistic 4D-Var NWP system solutions presented in Sect. 3. First, all the increments are proportional to the innovation, so the observations must contain information not already in the background. Second, the wind increment is proportional to the background tracer gradient. Hence, if the background gradient is zero, there is no wind increment. This is intuitively correct since, in the TLM, wind increments can only influence the tracer through the background gradients, not the increment gradients. Larger gradient regions will allow greater influence on the wind field, as illustrated in the full 4D-Var context by Peuch et al. (2000). Third, all of the increments have similar weighting or "gain" factors. The first term in the denominator of the weighting factors is proportional to $\sigma_{\mathrm{ob}}^{2}$. As $\sigma_{\mathrm{ob}}$ increases, all the increments decrease, so that the analysis moves toward the background state. The second term in the denominator of the weighting factor for the wind increment becomes large when $\sigma_{u}$ is smaller than $\sigma_{q}$. For very large $\sigma_{q} / \sigma_{u}$, the wind increment is near zero and the tracer increments dominate. The third term in the denominator of the weighting factor for tracer increments becomes large when $\sigma_{q}$ is smaller than $\sigma_{u}$, assuming the tracer gradient term is large enough. Varying the ratio $\sigma_{q} / \sigma_{u}$ is one way to reduce or increase the tracer-wind interaction in the assimilation. However, ideally the background error values should represent the real forecast error estimates. With only one observation the solution is underconstrained, and this ratio completely determines the partitioning between tracer and wind increments.

As an example, we evaluate the solution with a specified background wind error (relative to the "true" wind) of $40 \%$. The initial background state is $\boldsymbol{x}_{\mathrm{b}}\left(t_{0}\right)=(1,2,3,1.4)$. The truth, $\boldsymbol{x}_{t}\left(t_{0}\right)=(1,2,3,1.0)$, is propagated forward in time in order to simulate a "perfect" observation (so that $y\left(\lambda_{1}\right.$, $\left.t_{1}\right)=1.5$ ). The observation and background error standard deviations are set to $\sigma_{\mathrm{ob}}=0.1, \sigma_{q}=0.1$, and $\sigma_{u}=1.0$. The resulting analysis, illustrated in Fig. 1 , is $\boldsymbol{x}_{\mathrm{a}}\left(t_{0}\right)=(0.99,2.01$, $2.99,1.04)$. The analyzed wind is much closer to the true wind, and the initial tracer values have moved slightly away from the truth. Although the analysis state is different from the truth, it minimizes the cost function at a value of 0.07 compared to a cost function of 2.00 for the background.

The sensitivity of the wind analysis to observation and background tracer error standard deviations (with $\sigma_{u}$ fixed at 0.2 ), as well as to imposed random observation errors, is examined in Fig. 2, which illustrates the tracer-wind extraction for a range of error specifications and gradients for this one-observation case. The metric used in Fig. 2 is the "normalized wind increment," which we define as the analyzed wind increment divided by the ideal increment (the difference between the true wind and the background wind) and multiplied by 100. A normalized wind increment of $100 \%$ indicates perfect match of the analysis with the truth, while $0 \%$ indicates that the analysis matches the background. The solid curves show the solution for a "perfect" observation (calculated using the true wind). The dashed lines show the 1-sigma standard deviation of the solution when Gaussian random error is added to the observation with a standard deviation equal to $\sigma_{\mathrm{ob}}$.

It is clear that wind extraction is aided by large gradients in the background tracer field. As the gradient goes to zero, the solution will only increment the tracer field, not the wind field. In Fig. $2 \mathrm{a}, \sigma_{q}$ is kept at a small value $(0.1)$, which 
(a) Normalized Wind Increment with Background Tracer Error Stdev $=0.10$

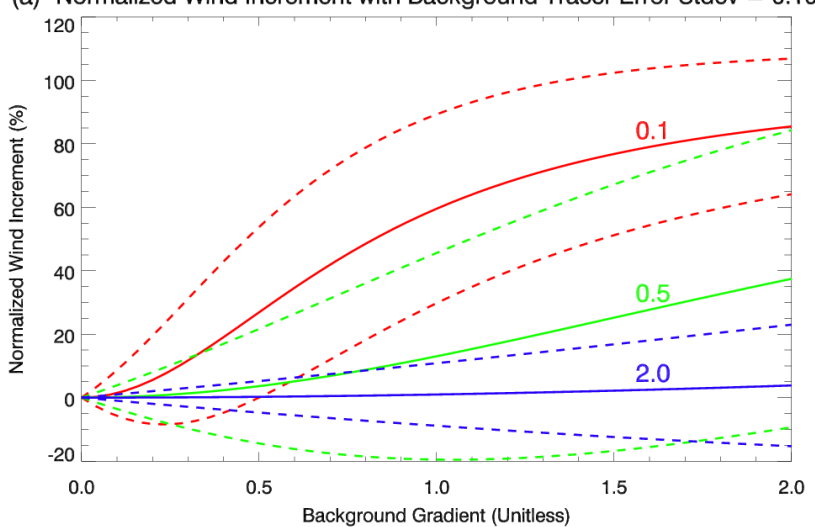

(b) Normalized Wind Increment with Observation Error Stdev $=0.10$

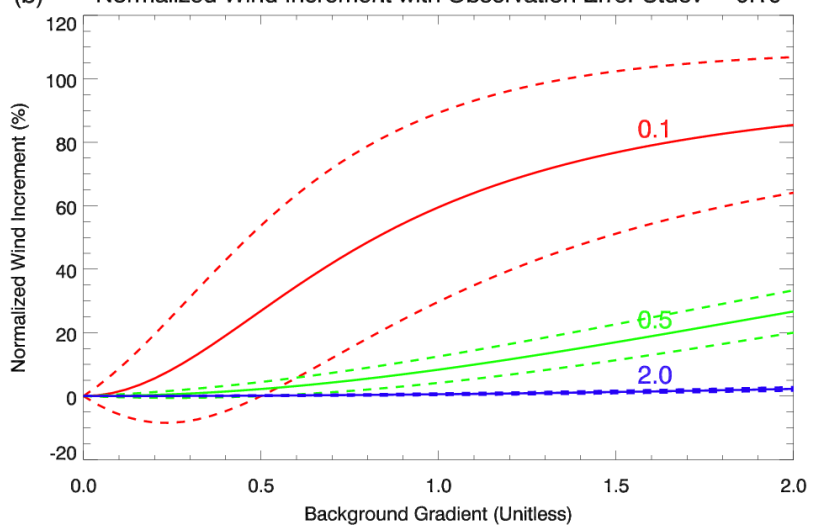

Fig. 2. Normalized wind increment as a function of the background tracer gradient for the case of one observation. $100 \%$ indicates that the analyzed wind equals the true wind. The solid line is the solution using one observation based on the true winds. The dashed lines represent the 1-sigma standard deviation of the solution for Gaussian random observation error $\sigma_{\mathrm{ob}}$. In (a) $\sigma_{q}$ is fixed at 0.1 and $\sigma_{\mathrm{ob}}$ is varied from 0.1 to 2.0 , as labeled. In (b) $\sigma_{\mathrm{ob}}$ is fixed at 0.1 and $\sigma_{q}$ is varied from 0.1 to 2.0 , as labeled.

tends to favor the incrementing of the wind rather than the tracer. For a small $\sigma_{\mathrm{ob}}$ of 0.1 , the normalized wind increment approaches $\sim 85 \%$ in our model when the gradient is large (2.0). As $\sigma_{\mathrm{ob}}$ increases, the mean wind recovery decreases and there is an increased probability that the analyzed wind is worse than the background wind (dashed lines fall below zero). Although in this one-observation case, the wind may become worse, if we were to take an ensemble of observations with random error $\sigma_{\mathrm{ob}}$ to produce an ensemble of analyses, more of the analyses would benefit from the tracer assimilation, even in the worst case scenarios presented in Fig. 2a. In a statistical sense, the overall influence of the tracer assimilation is positive, even if in certain cases the winds are degraded, as long as $\sigma_{\mathrm{ob}}$ is specified consistent with the actual observation errors. In Fig. $2 b, \sigma_{\mathrm{ob}}$ is kept small (0.1) while $\sigma_{q}$ is varied. Increasing $\sigma_{q}$ decreases the wind extraction because it favors tracer increments over wind increments.
Increasing $\sigma_{q}$ also prevents wind degradation (dashed lines move above or near zero), and is an effective way of reducing the tracer-wind interaction in $4 \mathrm{D}$-Var.

This 1-D illustration based on assimilation of one observation, although far from realistic, provides intuitive understanding of the process of tracer-wind extraction. Tracer observations impact the wind due to the use of the TLM in the cost function. The process is highly dependent on the geophysical factors such as the tracer gradient and background wind, on assimilation model parameters such as the background error standard deviations, on the details of the formulation of the TLM, on the observation error standard deviation, and on the quality of the observation. Before moving to the full 4D-Var problem, we next examine the 1-D problem with multiple observations.

\subsection{Solutions for multiple observations}

If we increase the number of observations, we would expect to enhance our ability to recover the correct wind. Here we present numerical solutions of the 1-D problem with tracer observations at all three grid points at $t_{1}$. The truth state $\boldsymbol{x}_{t}\left(t_{0}\right)$ is again used to construct "perfect" observations $\boldsymbol{y}=\left(q_{1}^{\mathrm{ob}}\left(t_{1}\right), q_{2}^{\mathrm{ob}}\left(t_{1}\right), q_{3}^{\mathrm{ob}}\left(t_{1}\right)\right)$ for a best case example. The observation error standard deviation is set to a small value, $\sigma_{\mathrm{ob}}=0.001$, so that the analysis will closely fit the observations. Note that we cannot set this term exactly to zero, because the cost function would become singular and no solution exists. An imperfect initial background state, $\boldsymbol{x}_{\mathrm{b}}\left(t_{0}\right)$, is chosen, and $\sigma_{q}$ and $\sigma_{u}$ are set to unity. We then numerically solve the $4 \mathrm{D}$-Var equations to obtain the analysis, $\boldsymbol{x}_{\mathrm{a}}\left(t_{0}\right)$. All the values listed below are for the initial time $t_{0}$.

Case 1: $\boldsymbol{x}_{\mathrm{b}}=(2.0,3.0,1.0,0.5) \boldsymbol{x}_{t}-\boldsymbol{x}_{\mathrm{b}}=(0.0,0.0$, $0.0,0.2) x_{\mathrm{a}}-x_{\mathrm{b}}=(-0.07,0.07,0.01,0.11)$

This case is similar to the single observation case presented in Sect. 2.2 in that a wind error is assumed (0.2), but the initial background tracer (at time $t_{0}$ ) equals the truth, $\boldsymbol{q}_{\mathrm{b}}\left(t_{0}\right)=\boldsymbol{q}_{t}\left(t_{0}\right)$. The background tracer at time $t_{1}$ differs from the truth due to advection by the imperfect wind field, $\boldsymbol{q}_{\mathrm{b}}\left(t_{1}\right) \neq \boldsymbol{q}_{t}\left(t_{1}\right)$, resulting in innovations with respect to the perfect observations. When the three tracer observations are assimilated, the analyzed wind error reduces by $\sim 50 \%$ (to 0.09). Small erroneous tracer increments move the analysis away from the initially perfect background. We can constrain the tracer further by adding a fourth tracer observation at the initial time that matches the truth (e.g., $\left.y\left(\lambda_{1}, t_{0}\right)=x_{t}\left(\lambda_{1}, t_{0}\right)\right)$. In this case the analyzed tracer moves much closer to the truth since we have as many observations as state vector elements, and the observations are "perfect." This situation does not represent realistic NWP systems. The imperfect simultaneous incrementing of winds and tracers illustrated that this case will be a general characteristic of 
realistic tracer-wind assimilation because of limited tracer sampling and significant errors in all forecast fields and observations.

Case 2: $\boldsymbol{x}_{\mathrm{b}}=(2.0,3.0,1.0,0.5) \boldsymbol{x}_{t}-\boldsymbol{x}_{\mathrm{b}}=(0.5,-0.2$, $0.3,0.0) x_{\mathrm{a}}-x_{\mathrm{b}}=(0.3,-0.25,0.32,-0.24)$

For case 2 the initial state includes "random" background tracer errors, but specifies the wind as the true wind. Again we assimilate three "perfect" tracer observations at time $t_{1}$. The analysis reduces the initial tracer errors, but also includes an erroneous wind increment of -0.24 , thereby decreasing the wind by $\sim 50 \%$. The analysis state is able to fit the three observations with a cost function that is smaller than the cost function that corresponds to the background state. However, this illustrates that in the presence of significant background tracer errors, assimilation of tracer observations has the potential to degrade the winds. However, if the background error covariances are correctly specified, the winds should not degrade in a statistical sense for an ensemble of assimilations with random observation errors.

Case 3: $x_{\mathrm{b}}=(2.0,3.0,1.0,0.5) \boldsymbol{x}_{t}-\boldsymbol{x}_{\mathrm{b}}=(0.1,0.1$, $0.1,0.0) x_{\mathrm{a}}-x_{\mathrm{b}}=(0.1,0.1,0.1,0.0)$

For the third case, we choose initial background tracer errors that represent a constant bias of 0.1 , but no wind error. This is a special case since a constant tracer bias does not change with advection, and without a spatial gradient in the innovations, the wind increment is always zero. The analysis for three tracer observations does very well at correcting the tracer bias because we have perfect observations at every grid point. If we reduce the number of observations to just one (at grid point 1), this results in an erroneous $5 \%$ decrease in the analyzed wind (to 0.45 ). Undersampling of the tracer field in the presence of a constant background tracer bias may adversely affect the wind. A bias correction scheme may help alleviate this problem, but this may be complicated by observation biases and/or inadequate photochemical parameterizations in the forecast model.

The results from these test cases, although highly idealized, are useful for demonstrating some of the limitations of tracer-wind extraction that have been identified in previous studies (Daley, 1995; Riishøjgaard, 1996; Peuch et al., 2000; Semane et al., 2009). First, geophysical distributions (i.e., tracer gradients and orientation with respect to wind) must be sufficient for wind extraction. Second, observations must be sufficiently accurate and their errors correctly specified. Third, observations must be sufficiently dense in order to extract wind information. Fourth, the background tracer must be unbiased, or the tracer field must be sufficiently sampled to identify the bias. In addition, as shown in Sect. 2.2, correct specification of background and observation error standard deviations is required to optimally extract wind information in the presence of noisy or sparse data. We now move on to examine how some of these limitations are revealed in more realistic 4D-Var simulations.

\section{NAVGEM ozone experiment}

\subsection{Experimental procedure}

The models presented in Sect. 2 demonstrate the potential of using tracer observations to constrain wind fields in time-dependent variational assimilation, but also illustrate many of the limitations of this approach. Extending the approach to a more realistic setting, in this section we describe wind extraction experiments that use a development version of NAVGEM with the 4D-Var assimilation algorithm NAVDAS-AR (Xu et al., 2005; Rosmond and Xu, 2006). NAVGEM is the successor to the Navy Operational Global Atmosphere Prediction System (NOGAPS) (Hogan and Rosmond, 1991). New features in this version of NAVGEM and NAVDAS-AR include a semi-Lagrangian transport scheme, variational bias correction for satellite radiance assimilation, the simplified Arakawa-Schubert convection scheme, and trace gas assimilation. For simplicity, the combined system with NAVDAS-AR and the semi-Lagrangian forecast model will be referred to as NAVGEM, with the caveat that we are using a preoperational development version.

The NAVGEM outer-loop configuration (used for calculating the background, the truth, and the innovations) for this study has a horizontal resolution based on spectral triangular truncation T239 $\left(\sim 0.5^{\circ}\right.$ Gaussian grid spacing for latitude, $0.5^{\circ}$ grid for longitude), while the inner loop (used for solving the analysis $)$ is run at $\mathrm{T} 119\left(\sim 1.0^{\circ}\right.$ Gaussian grid spacing for latitude, $1.0^{\circ}$ grid for longitude). Both are run with 60 vertical levels with model top at $0.005 \mathrm{hPa}$ (approximate vertical spacing of 1-2 km, varying with altitude) and with a time step of $450 \mathrm{~s}$. The vertical grid is a hybrid sigma-pressure grid that transitions to pure pressure levels at $\sim 87 \mathrm{hPa}$. Note that the outer loop resolution and number of vertical levels differs from the currently operational model (T319 with 50 levels). The ozone analysis uses observations from the Aura MLS. The MLS Version 2 ozone data (Froidevaux et al., 2008) were assimilated in the model for several weeks in order to generate a realistic ozone analysis for initializing the "truth" forecast as described below.

In order to test ozone-wind extraction in this system, we designed an experiment in which simulated ozone measurements are assimilated into NAVGEM. The time period of January 2009 was chosen because of the dynamic activity that accompanied the unusually large 2009 Arctic stratospheric major warming (Manney et al., 2009; Lahoz et al., 2011). The winter stratosphere is generally a location with large horizontal ozone gradients, making wind extraction favorable, as explained in Sect. 2. During the major warming, strong ozone advection occurs as the vortex splits apart into 
(a)

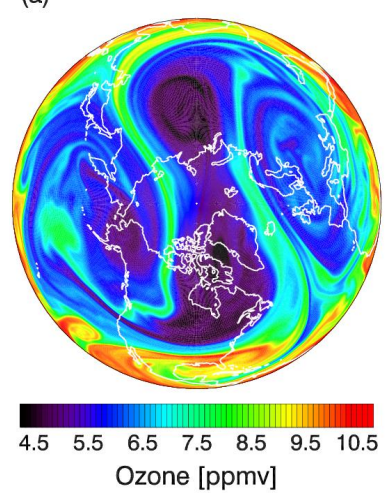

(b)

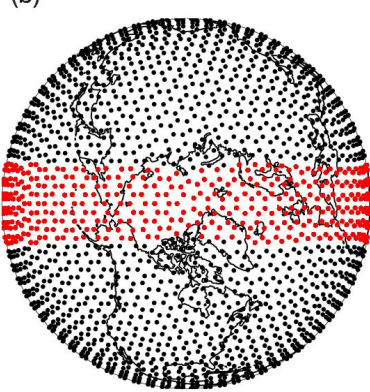

Fig. 3. (a) Forecast ozone (used for the "truth") over the Northern Hemisphere at $11.4 \mathrm{hPa}(\sim 30 \mathrm{~km})$ after $51 \mathrm{~h}(03: 00 \mathrm{Z}$ on 22 January 2009). Red (blue) indicates high (low) values of ozone. (b) The sampling grid used for the experiment. There are 3840 points over the globe, with an average spacing of approximately $300 \mathrm{~km}$. The red dots indicate the observations that are used for the case where the data are subsampled to resemble a fictitious polar-orbiting satellite (see text for details).

two pieces. This event therefore provides an excellent case study to test the wind extraction process. Note that in this full 3-D simulation, vertical ozone gradients may also play a role in the wind extraction due to the vertical advection term in the linearized ozone continuity equation. This role is of second order, however, because the vertical advection of tracers in the stratosphere is much weaker than horizontal advection over short timescales (Plumb, 2002). The influence of vertical gradients will not, therefore, be discussed in this paper.

The approach follows a similar design to that used in the fully idealized "OZONE" simulation included in Peuch et al. (2000). The first step is to generate the "truth" simulation. This is a 3-day forecast initialized at $00: 00 \mathrm{Z}$ on $20 \mathrm{Jan}$ uary 2009 using the NAVGEM analyzed ozone and dynamical fields. A snapshot of the ozone at $11.4 \mathrm{hPa}(\sim 30 \mathrm{~km}) 51 \mathrm{~h}$ into the forecast $(03: 00 \mathrm{Z}$ on 22 January 2009$)$ is provided in Fig. 3a. The polar vortex, marked by low ozone mixing ratio, has been stretched into an elongated dumbbell shape. There are strong gradients throughout much of the Northern Hemisphere, indicating strong potential for wind extraction. The global ozone data were saved at hourly intervals along the forecast on the model Gaussian grid.

The second step is to produce the simulated observations. An approximately equal area sampling was generated by subdividing an icosahedral base into a triangular grid with 3840 elements (see Fig. 3b), which has a horizontal resolution of $\sim 300 \mathrm{~km}$. To avoid any horizontal interpolation of the background ozone, measurement locations were chosen as the nearest NAVGEM latitude/longitude grid points to the circumcenters of the triangles. The measurements are simulated on the NAVGEM vertical grid, so vertical interpolation of the background is avoided as well. Sixteen vertical levels in the
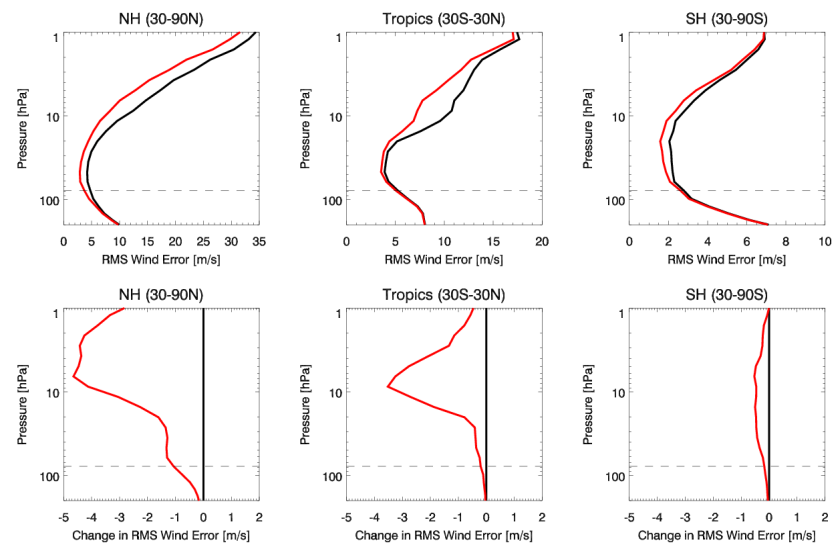

Fig. 4. (Top) The background (black) and analyzed (red) RMS vector wind error as a function of pressure in three latitude bands for the case of "perfect" ozone observations (i.e., observations based on the truth with no imposed random errors) with specified observation error standard deviation $\sigma_{\mathrm{ob}}$ of $0.1 \mathrm{ppmv}$. (Bottom) The differences between the analyzed and the background RMS wind errors. Negative values indicate improvements to the wind field due to tracer assimilation. The horizontal dashed line at $78 \mathrm{hPa}$ indicates the lowest level of the observations. All plots are for 06:00 Z on 22 January 2009.

stratosphere are used, ranging from 78 to $1.2 \mathrm{hPa}(\sim 20$ to $50 \mathrm{~km}$ altitude). Simulated ozone measurements were generated at each observing location for each forecast hour. For the assimilation of these observations, the observation error covariance is specified as uncorrelated with a constant standard deviation $\sigma_{\mathrm{ob}}$ of $0.1 \mathrm{ppmv}$ (unless otherwise specified). We will examine cases with "perfect" observations (i.e., based on the "truth" simulation with no random error or bias added) and with the addition of random error. Note that although the observations are called "perfect", we do not set $\sigma_{\mathrm{ob}}$ exactly to zero, but to a reasonably small value. Setting $\sigma_{\mathrm{ob}}$ to zero causes the cost function (Eq. 4) to become singular and prevents the solution from converging.

The third step involves choosing initial conditions that produce a background forecast with the desired error characteristics. We choose to create a background forecast in which the ozone errors are forced only by wind errors. The initial (time $=0$ ) background ozone field must be perfect, but the initial background dynamical fields (fields other than ozone) must be imperfect. Although the initial ozone is perfect, ozone errors develop over the $6 \mathrm{hr}$ background forecast due to advection by imperfect winds. We create imperfect initial dynamical conditions by using fields from the truth simulation that are mismatched by 2 days (i.e., using the 20 January dynamical fields to initialize an assimilation cycle for 22 January), but use the true ozone field (corresponding to 22 January) for the initial ozone. This approach creates a dynamically balanced initial state, but one that differs from the "true" state. The 2-day mismatch results in much larger initial wind errors than expected in a typical operational system. 

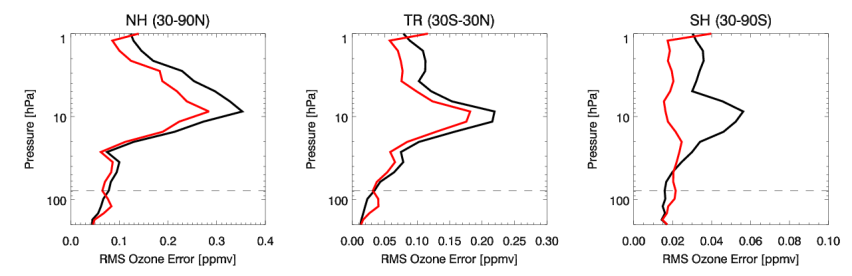

Fig. 5. The background (black) and analyzed (red) RMS ozone errors for the case of "perfect" ozone observations (i.e., based on the truth with no imposed random errors) with specified observation error standard deviation $\sigma_{\mathrm{ob}}$ of 0.1 ppmv. All plots are for 06:00 Z on 22 January 2009.

We choose this approach in order to create large background ozone errors (and therefore large innovations) that enhance the wind extraction mechanism. The background root-meansquare (RMS) vector wind errors (relative to the "true" winds generated from the 3-day forecast) resulting from this 2-day mismatch are shown in Fig. 4 (black lines) for three latitude bands: Northern Hemisphere $(\mathrm{NH})\left(30-90^{\circ} \mathrm{N}\right)$, the tropics $\left(30^{\circ} \mathrm{S}-30^{\circ} \mathrm{N}\right)$, and Southern Hemisphere (SH) $\left(30-90^{\circ} \mathrm{S}\right)$. Note that throughout the rest of the paper "RMS wind error" is used as shorthand for "RMS vector wind error," which is the square root of the sum of the RMS zonal wind error and the RMS meridional wind error. Because the RMS wind errors are similar throughout the background forecast, we will plot the errors at the "analysis" time, which is the central time of the $6 \mathrm{~h}$ analysis window (in this case $06: 00 \mathrm{Z}$ on $22 \mathrm{Jan}-$ uary 2009).

The background RMS wind errors are largest in the winter hemisphere, with values of $\sim 5 \mathrm{~m} \mathrm{~s}^{-1}$ in the lower stratosphere, increasing to $\sim 30 \mathrm{~m} \mathrm{~s}^{-1}$ in the upper stratosphere, while in the SH the errors are less than $7 \mathrm{~m} \mathrm{~s}^{-1}$ throughout the pressure range under consideration $(200-1 \mathrm{hPa})$. Unlike the winds the background RMS ozone errors (relative to the "true" ozone) start at zero ("perfect" initial ozone) and grow in time during the assimilation window due to errors in the background winds. The background RMS ozone errors are shown in Fig. 5 (black lines) for the analysis time. Similar to the background RMS wind errors, the ozone errors are large in the NH and tropics, while in the SH they are very small. This suggests that even for the large wind errors simulated here, an ozone measurement precision better than $0.1 \mathrm{ppmv}$ would be required to detect wind-error-induced $\mathrm{OmF}$ values in the $\mathrm{SH}$ and in the tropical and $\mathrm{NH}$ lower stratosphere. The design of this experiment represents a best case scenario for extracting wind information because the resulting OmF values are only a function of background wind errors. There are no correlations between ozone and other fields in the specified background error covariance, so advection by the TLM over the $6 \mathrm{~h}$ assimilation window is the only mechanism that connects ozone with the dynamical fields in the assimilation algorithm.
The final step is to assimilate ozone observations and evaluate the analysis relative to the truth. NAVGEM uses a $6 \mathrm{~h}$ time window with the observations binned at $0.5 \mathrm{~h}$ intervals. Since the simulated observations fall directly on one hour intervals, there is no time-binning error (the TLM time step of $450 \mathrm{~s}$ results in exactly eight time steps between observation intervals). The background error covariances are specified in the assimilation algorithm as follows. The background ozone error standard deviation $\sigma_{q}$ has a constant value of 0.2 ppmv. The horizontal and vertical spatial correlation lengths for ozone are $385 \mathrm{~km}$ and $\sim 1.3 \mathrm{~km}$, respectively. The background error covariance for the other fields is based on the dynamically balanced model used operationally (Daley and Barker, 2001). The wind error standard deviations $\sigma_{u}$ increase with altitude from $\sim 3 \mathrm{~m} \mathrm{~s}^{-1}$ at $100 \mathrm{hPa}$ to $\sim 6.5 \mathrm{~m} \mathrm{~s}^{-1}$ at $6 \mathrm{hPa}$. These values are similar to the SH background RMS wind errors in our experiment (see Fig. 4), but are much smaller than the NH background RMS errors. No further attempt has been made to modify the background error standard deviations to exactly match the forecast error in this experiment. The TLM does not incorporate ozone chemistry, but this should not be very important over the short time scales of the assimilation window, except possibly in the upper stratosphere. For this study, only one assimilation cycle was performed, with the analyzed winds at $06: 00 \mathrm{Z}$ on 22 January used for verification.

\subsection{Limitations due to geophysical conditions}

The analyzed RMS wind errors (relative to the "truth" forecast that was used to simulate the observations) following ozone assimilation are shown in the red lines on Fig. 4 (top row), and the change in RMS wind error (i.e., analyzed RMS wind error - background RMS wind error) is shown on Fig. 4 (bottom row). The analyzed RMS wind errors are smaller than the background errors in all three latitude bands over the altitude range of the observations. This verifies that the tracer-wind extraction mechanism is working for the observation coverage and quality simulated in this study. The reduction in RMS wind error is largest in the $\mathrm{NH}$ and tropics, as expected, with differences of up to $\sim 4 \mathrm{~m} \mathrm{~s}^{-1}$, peaking above $10 \mathrm{hPa}$. The magnitude of these differences is similar to the results of Peuch et al. (2000), but the altitudes at which the largest impact occurs is different. Peuch et al. (2000) assimilated $12 \mathrm{~h}$ of simulated total column ozone data and found the largest impact on winds in the upper troposphere/lower stratosphere, consistent with the fact that total ozone variability is dominated by transport processes in this region. Our study finds the dynamical impact of simulated ozone profile assimilation to peak in the middle and upper stratosphere. For ozone measurements with larger vertical weighting functions or with vertical dependence of quality, we would expect the dynamical impact as a function of altitude to be different. The change in RMS wind error is large in the tropical middle to upper stratosphere, but is small below $\sim 30 \mathrm{hPa}$ in the 
tropics. The change in RMS wind error in the tropics qualitatively resembles the tropical ozone mixing ratio profile, with a peak at $\sim 10 \mathrm{hPa}$, and decreasing monotonically above and below. Because $\sigma_{\mathrm{ob}}$ is constant in mixing ratio, the relative errors will be smaller in regions of larger ozone mixing ratios, such as in the tropical middle stratosphere, so we expect to have a larger impact here. If observations have errors proportional to the mixing ratio, this would result in different wind extraction characteristics. However, independent of observation error, the strength of the horizontal ozone gradients and cross-gradient winds also play a major role in determining the effectiveness of wind extraction.

In the $\mathrm{SH}$ the change in RMS wind error is quite small (less than $\sim 0.5 \mathrm{~m} \mathrm{~s}^{-1}$ ). This is due to the summer stratospheric flow being much less disturbed by upward-propagating planetary waves, causing near-zonal flow that is much less variable and therefore easier to forecast in the absence of tracer information. However, the winter stratosphere is very dynamic, particularly during such events as major or final warmings, so the error growth rate is expected to be large. The analysis for these conditions is not very sensitive to the background ozone error standard deviation, since removing the ozone from the control variable (effectively setting the initial background ozone error standard deviation to zero) results in essentially the same wind analyses (not shown). This is because the ozone OmFs were designed to correspond to wind errors only; the ozone $\mathrm{OmF}$ values at the beginning of the time window are then zero, which would tend to suppress ozone increments. As seen in Fig. 5, the differences between background and analyzed RMS ozone errors are rather small, suggesting the largest impact of the ozone assimilation is on the dynamical fields, rather than on ozone itself.

Figure 6a presents a latitude/pressure cross section of the change in RMS wind error (difference between analyzed and background RMS wind errors). Ozone assimilation is benefitting the winds throughout the $\mathrm{NH}$ upper stratosphere, where the dynamics of the major warming are causing strong ozone advection. This reduction in RMS wind errors extends to pressures higher than $78 \mathrm{hPa}$ in many locations, suggesting that assimilation of stratospheric tracer fields has an impact not only on the stratospheric analyses, but also on the upper tropospheric winds. This is likely attributed to vertical error correlations in the background error covariances (Daley and Barker, 2001). A few locations - most notably in the tropical upper troposphere, $\mathrm{NH}$ polar lower stratosphere, and $\mathrm{SH}$ upper stratosphere - show a slight degrading of the winds (indicated by white regions). The latter may be partly caused by ozone photochemistry. The forecast model used to generate the observations includes parameterized chemistry, but the tangent linear model does not. In the upper stratosphere, this can cause problems, since the ozone photochemistry is relatively fast with photochemical relaxation times of less than a day (Coy et al., 2007). In general, if the photochemical terms in the ozone continuity equation are of the same magnitude as the advection terms, the errors in the TLM from neglect of photochemistry will be significant.

As discussed in Sect. 2, wind extraction is closely related to the innovations. In our simulations the innovations depend on the orientation of the wind errors with respect to background horizontal tracer gradients. Figure $6 \mathrm{~b}$ shows the latitude/pressure cross section of RMS innovations for this simulation. There are large innovations in the NH middle and upper stratosphere, colocated with large changes of RMS wind error (Fig. 6a). In regions of small innovation the wind error reduction is also small. This is also consistent with the results from Daley (1996), which show that when the constituent time tendency is small, wind extraction will be difficult. For the summer stratosphere the winds are generally zonal and steady. Under such conditions, tracer fields eventually become aligned with the streamfunction (Rhines and Young, 1983). When this occurs, the wind is aligned perpendicular to the tracer gradients and the advection term becomes small (see also Salby and Juckes, 1994). These results indicate that the system is working consistently with expectations gained from the simple 1-D model, and that tracer innovation plots are useful for identifying regions where wind extraction is feasible. Other tracers besides ozone may have gradients that facilitate wind extraction in different regions due to differing sources/sinks and photochemistry. Using innovation plots made from other tracers, one can ascertain information about where each tracer will be able to influence the winds.

Although Fig. 6a may suggest that wind improvements are uniform across the $\mathrm{NH}$ upper stratosphere, horizontal maps of the change in vector wind error show that the actual situation is rather complicated. Figure $6 \mathrm{c}$ shows the wind error change at $11.4 \mathrm{hPa}$ as a function of longitude and latitude in the $\mathrm{NH}$, overlaid with $11.4 \mathrm{hPa}$ geopotential height contours (white lines). There are significant regions of improved wind over the $\mathrm{NH}$, particularly in the polar vortex, indicated by the dumbbell-shaped geopotential height contours (see also Fig. 3a), and in the tropical Pacific region. Regions of degraded wind occur around the anticyclonic regions that flank both sides of the polar vortex (closed geopotential height contours in the Aleutian and European regions) and in the tropics. In the SH (Fig. 6d), marginal wind vector changes (less than $\sim 2 \mathrm{~m} \mathrm{~s}^{-1}$ ) cover the majority of the hemisphere, with larger changes in the tropics. While the impact of tracer assimilation is very weak in the SH summer conditions, the dynamical conditions in the $\mathrm{NH}$ winter lead to a much stronger influence of the tracer field on the winds.

In Fig. 7 we examine background and analyzed mean errors of the zonal and meridional wind, to supplement the RMS results shown in Fig. 4. In the NH the analyzed mean zonal wind error is smaller (in absolute value) than the background error over the entire range from 200 to $1 \mathrm{hPa}$, with maximum improvement of $\sim 2 \mathrm{~m} \mathrm{~s}^{-1}$ around $6 \mathrm{hPa}$. The impact on the mean meridional wind in the $\mathrm{NH}$ is weaker, with slight improvement from $\sim 78$ to $5 \mathrm{hPa}$ and slight degradation from $\sim 5$ to $2 \mathrm{hPa}$. That zonal winds in the $\mathrm{NH}$ are 


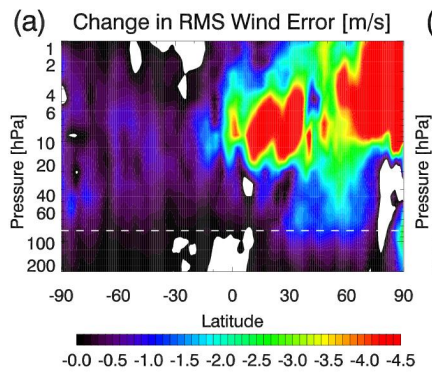

(b) RMS Ozone Innovation [ppmv]

(c)

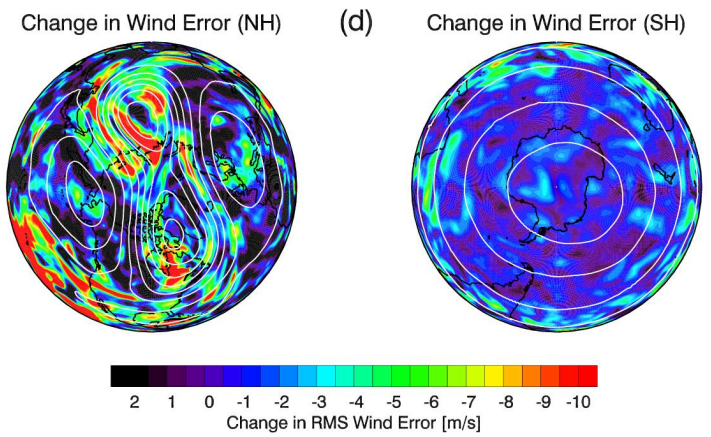

Fig. 6. (a) The change in RMS vector wind error (analyzed - background) as a function of latitude and pressure for 06:00 Z on 22 January 2009. Red (blue) indicates large (small) error reduction. White indicates increasing errors. (b) RMS ozone innovation as a function of latitude and pressure calculated using all observations in the $6 \mathrm{~h}$ window. (c) Change in vector wind error over the $\mathrm{NH}$ overlaid with the geopotential height contours (white lines) at $11.4 \mathrm{hPa}$ for 06:00 Z on 22 January 2009. (d) Same as (c), but for the SH.

influenced more than the meridional winds is likely due to the larger background zonal wind errors combined with significant background tracer gradient in the zonal direction caused by the splitting of the vortex during the major warming (see Fig. 3a). In the tropics and $\mathrm{SH}$, the impact of ozone assimilation on the mean winds is very small relative to the RMS differences (Fig. 4), with regions of both slight improvement and slight degradation.

It is clear from this analysis that the ability of the 4D-Var system to extract wind information is strongly dependent on geophysical factors. These include the background ozone gradients and the initial wind errors, which convolve via the advection equation to produce ozone innovations. Although regions of both improved and degraded winds occur in the NH mid-stratosphere (Fig. 6c), the overall impact on the winds is positive, as seen in Fig. 6a. Analyses of other dynamical situations, as well as other trace gases than ozone, will result in wind extraction in different geophysical regions. We now move on to examine the limitations of wind extraction due to observation errors and how they are characterized in the 4D-Var system.
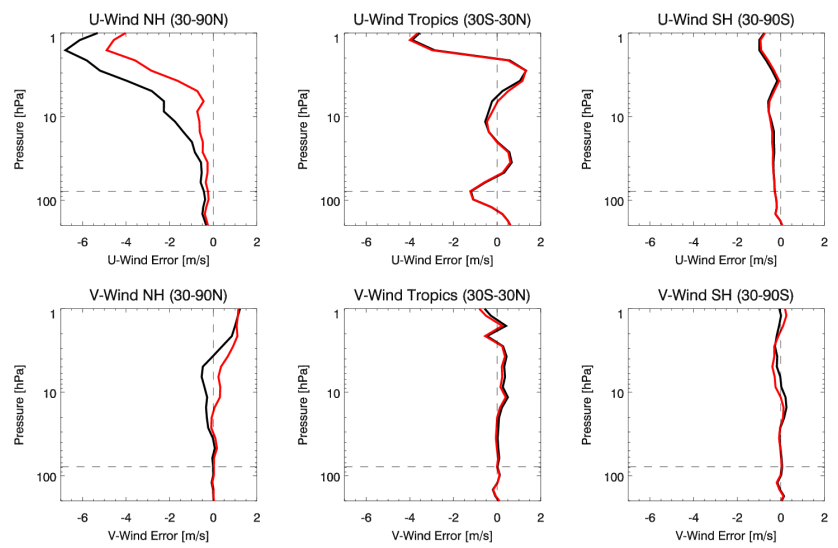

Fig. 7. (Top row) The background (black) and analyzed (red) mean zonal wind error as a function of pressure in three latitude bands for the case of perfect ozone observations (i.e., based on the truth with no imposed random errors) with specified observation error standard deviation $\sigma_{\mathrm{ob}}$ of $0.1 \mathrm{ppmv}$. (Bottom row) Same as top row, but for mean meridional wind error. The horizontal dashed line at $78 \mathrm{hPa}$ indicates the lowest level of the observations. All plots are for 06:00 Z on 22 January 2009.

\subsection{Limitations due to observation errors and observation error specifications}

Up to this point, the observations have been "perfect" in the sense that they are generated directly from the "truth" forecast with no imposed error. We now examine cases where Gaussian random errors of $2 \%, 5 \%$, and $10 \%$ of the ozone mixing ratio are applied to all data. In each case the specified $\sigma_{\mathrm{ob}}$ is also set to the same percent value, as in the simulations by Peuch et al. (2000). The resulting analyzed RMS wind errors are shown in Fig. 8. In all three latitude bands, increased observation error results in smaller changes in RMS wind error. In none of these cases does adding ozone errors result in increased RMS wind errors since $\sigma_{\mathrm{ob}}$ is specified consistently with the imposed observation errors. This result differs from Peuch et al. (2000), where imposed random observation errors of $3 \%$ or larger in the total column ozone field resulted in a global degrading of the winds. One major difference between the two studies is that we are assimilating profiles of ozone mixing ratio, whereas Peuch et al. (2000) assimilated the vertically integrated total column amount.

We also tried a case with imposed random observation errors of $5 \%$, but with the specified $\sigma_{\mathrm{ob}}$ set to a constant 0.1 ppmv, which is less than the $5 \%$ random error in most of the middle stratosphere. The resulting analysis (Fig. 9) shows reductions in RMS wind error in the $\mathrm{NH}$ and the tropics above about $20 \mathrm{hPa}$. However, in the SH, the RMS wind error increases in the pressure range from $\sim 30$ to $2 \mathrm{hPa}$. This is because in the $\mathrm{SH}$, the $5 \%$ imposed random observation error is much larger than the true OmF values, and the assimilation is constrained too tightly to the noisy data. This illustrates the fact that assimilating noisy ozone data in regions 

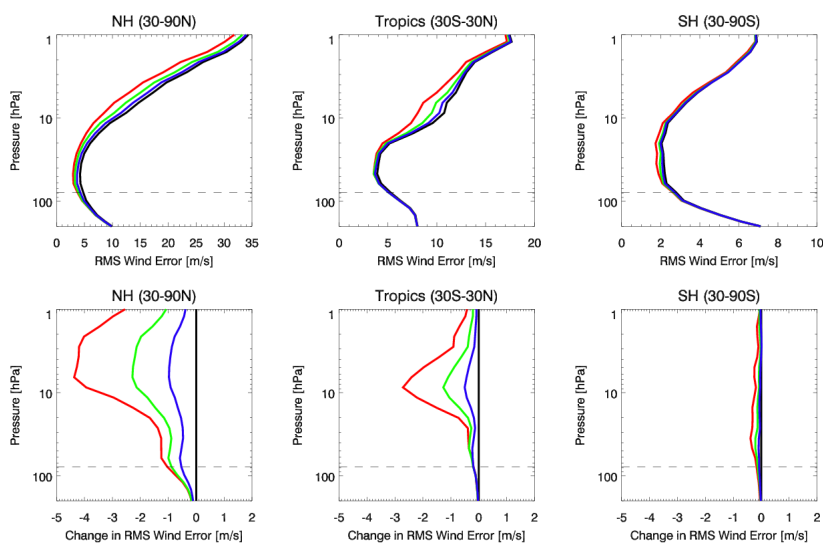

Fig. 8. As in Fig. 4, but for the cases with imposed random observation errors of $2 \%$ (red), $5 \%$ (green), and $10 \%$ (blue). All plots are for 06:00 Z on 22 January 2009.
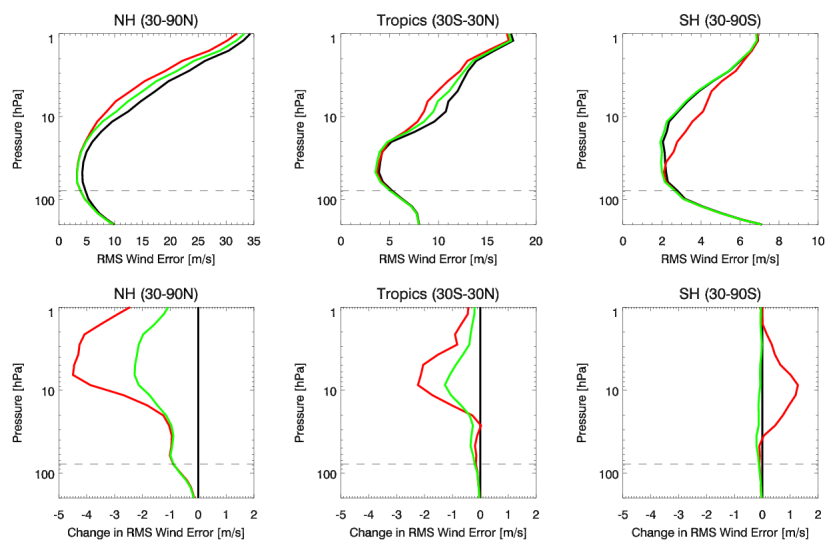

Fig. 9. As in Fig. 4, but for the case of imposed observation errors of $5 \%$, and with specified observation error standard deviation $\sigma_{\mathrm{ob}}$ of $5 \%$ (green) and $0.1 \mathrm{ppmv}$ (red). All plots are for 06:00 Z on 22 January 2009.

of weak tracer tendency can harm the analyzed winds if the observation error covariances are poorly specified.

\subsection{Limitations due to sampling patterns}

Wind extraction is also sensitive to the tracer sampling pattern used. The observation sampling of 3840 evenly distributed profiles every hour clearly provides sufficient coverage to extract wind in certain regions (especially $\mathrm{NH}$ and tropics). This original sampling pattern can be subsampled to resemble a fictitious polar-orbiting instrument. For this purpose the global grid was subsampled using a 26-degree wide swath that circles the globe (see Fig. 3b). Each hour, the swath shifts 26 degrees in longitude so that global coverage is achieved after $7 \mathrm{~h}$. This simulates a fictitious satellite with 90-degree inclination orbit, $60 \mathrm{~min}$ period, and which measures at exactly $1 \mathrm{~h}$ intervals.
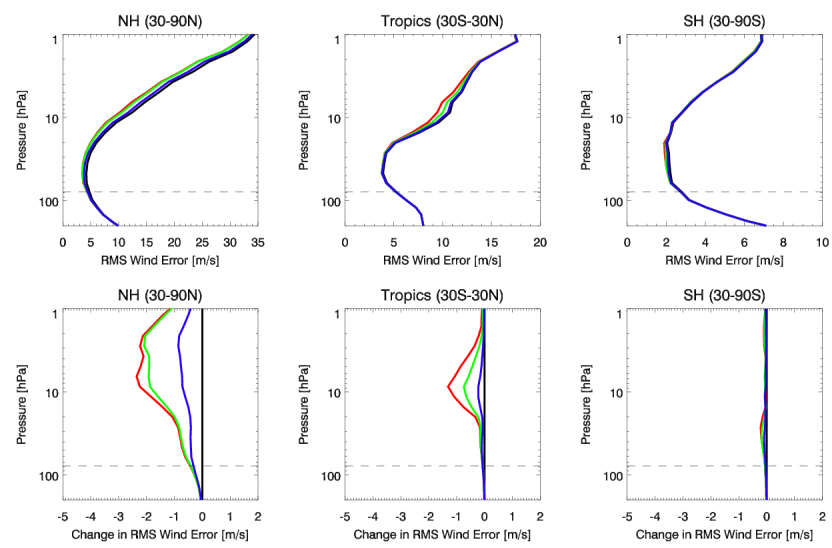

Fig. 10. As in Fig. 4, but for the case of data subsampled at $1 / 7$ of the globe each hour (see Fig. 3b for sampling pattern) for the cases of all perfect data (red), $2 \%$ imposed observational error (green), and $5 \%$ imposed observational error (blue). All plots are for 06:00 Z on 22 January 2009.

The results for the case of these "perfect," but sparser, observations and for $2 \%$ and $5 \%$ imposed random error are shown in Fig. 10. Wind extraction is achieved with this reduced sampling, but the effectiveness is severely reduced from the case where all observations are used (compare with Fig. 4). Particularly for the $5 \%$ error, a typical value for the uncertainty of MLS ozone in the stratosphere (Froidevaux et al., 2008), there is very little change in RMS wind error in the tropics, and virtually none in the SH. Wind extraction using a limb-viewing or single-angle nadir-viewing instrument such as MLS and SBUV will be even more difficult, and will not likely provide significant wind information except in the dynamically active winter hemisphere. Improvements to the winter stratosphere are particularly important, however, since this is the season when the dynamical coupling with the troposphere is greatest (Baldwin et al., 2003). The study by Semane et al. (2009), which used MLS observations, found a reduction in the 3-month mean wind bias, but not in the standard deviation. The experiments considered in our paper use a perfect model (i.e., no mean biases) with only one update cycle. More realistic experiments will be necessary for a direct comparison with the Semane et al. (2009) results.

\section{Summary}

The limitations of wind extraction from ozone assimilation are explored in this study using a simple 1-D time-dependent variational illustration as well as idealized 4D-Var experiments. Both are performed without correlations between the winds and tracer in the initial background error covariance. The wind extraction is therefore accomplished via the adjoint of the linearized tracer continuity equation. The 1-D illustration uses an analytic solution for a single tracer observation and numerical solution for multiple observations 
to demonstrate the dependence of wind extraction on background tracer gradient, observation quality, observation sampling, and specification of the background and observational error characteristics. Although highly idealized, the 1-D solutions are useful for highlighting some of the limitations of wind extraction to be expected in the full 4D-Var approach, particularly the necessity of correctly specifying observation error standard deviation in order to avoid degrading the wind.

The NAVGEM 4D-Var experiments use simulated, globally distributed ozone profiles with a vertical resolution equal to that of the forecast model. The observations are fictitious, in that they have vertical resolution attainable only by limbviewing instruments, but have global horizontal sampling resembling multiple nadir sensors. The simulations take place during the unusually large 2009 Arctic stratospheric major warming, which provided large Northern Hemisphere ozone gradients that are conducive to wind extraction, as shown in the results. The 4D-Var experiments demonstrate that reduction of RMS wind errors is possible, but with limitations due to geophysical conditions, tracer observation quality and error specifications, and observation sampling pattern. Ozone provides more dynamical information in the winter and tropical stratosphere, and less in the summer. Adding random observation errors limits the ability to extract wind, but the overall impact on the analyzed winds remained positive as long as the observation error standard deviation in the assimilation system was specified consistently with the imposed random errors. If the observation error standard deviation is underestimated, RMS wind errors may indeed increase. An experiment was also performed with a reduced sampling pattern that coarsely resembles a polar-orbiting satellite (while retaining the same high vertical resolution). Wind extraction was still possible with the reduced sampling, but the wind improvement was much less than the case of globally uniform sampling, particularly in the tropics and Southern Hemisphere.

\section{Conclusions}

This paper examines the limitations of wind extraction from the 4D-Var assimilation of ozone due to geophysical variability, observation quality, observation and background error specifications, and observation sampling. In our 4D-Var experiments, the initial background ozone field was always perfect (based on the truth) in order to provide a best case scenario for quantifying the ozone-wind interaction. Because perfect background ozone cannot be maintained while cycling the assimilation with imperfect winds, only one update cycle was used. A complete observing-system simulation experiment (OSSE) would require multiple update cycles using the full suite of operational meteorological observations. It is possible that background ozone errors that develop and persist in a full OSSE will destroy much of the wind improvement seen in our idealized experiments. In addition, the use of a 2-day mismatch in the initial dynamical conditions results in larger initial wind errors than those in a typical sixhour update cycle. This facilitates large ozone innovations and exaggerates the component of ozone innovations due to advection errors. We cannot therefore extend our conclusions directly to an operational setting. However, even if a further degradation of the wind impact may be demonstrated in an OSSE, one main message is that within the present idealized study, the limits of wind extraction can be demonstrated by increasing errors and reducing coverage towards real-world conditions.

In the future we plan to examine wind extraction in more realistic settings and using other tracers besides ozone since differing tracer gradients may allow wind extraction in different regions. One difficulty in using multiple tracers is the specification of photochemical sources and sinks, which must be sufficiently accurate to maintain a realistic background tracer field. Another important future study is to incorporate a background error covariance calculated from an ensemble forecast system. An ensemble-based error covariance would contain explicit wind-tracer correlations in the initial background error covariance and would thereby increase the wind-tracer interactions, especially for observations near the beginning of the assimilation time window. A recent paper by Milewski and Bourqui (2011) has shown promising results in which assimilating ozone observations with an ensemble Kalman filter in a chemistry-climate model can directly benefit the wind analyses via wind-tracer cross covariances.

Acknowledgements. We would like to thank those responsible for the development of NAVDAS-AR and the semi-Lagrangian forecast model used in NAVGEM. NAVDAS-AR was originally developed with ONR and PMW-120 funding under NRL base program elements $0601153 \mathrm{~N}$ and $0602436 \mathrm{~N}$. This work was supported in part by a grant of computer time from the DOD High Performance Computing Modernization Program at the US Army Engineer Research and Development Center. This work was funded by the Office of Naval Research. We also acknowledge helpful comments on the manuscript from Alan Geer and one anonymous referee.

Edited by: W. Lahoz

\section{References}

Andersson, E., Pailleux, J., Thepaut, J. N., Eyre, J. R., Mcnally, A. P., Kelly, G. A., and Courtier, P.: Use of cloud-cleared radiances in three/four-dimensional variational data assimilation, Q. J. Roy. Meteor. Soc., 120, 627-653, 1994.

Baldwin, M. P., Stephenson, D. B., Thompson, D. W. J., Dunkerton, T. J., Charlton, A. J., and O'Neill, A.: Stratospheric memory and skill of extended-range weather forecasts, Science, 301, 636-640, 2003.

Coy, L., Allen, D. R., Eckermann, S. D., McCormack, J. P., Stajner, I., and Hogan, T. F.: Effects of model chemistry and data 
biases on stratospheric ozone assimilation, Atmos. Chem. Phys., 7, 2917-2935, doi:10.5194/acp-7-2917-2007, 2007.

Daley, R.: Estimating the wind field from chemical-constituent observations: experiments with a one-dimensional extended Kalman filter, Mon. Weather Rev., 123, 181-198, 1995.

Daley, R.: Recovery of the one and two dimensional windfields from chemical constituent observations using the constituent transport equation and an extended Kalman filter, Meteorol. Atmos. Phys., 60, 119-136, 1996.

Daley, R. and Barker, E.: NAVDAS Source Book 2001, Naval Research Laboratory Publication NRL/PU/7530—01-441, 163 pp., available at http://www.dtic.mil/docs/citations/ADA396883, 2001.

Dragani, R. and McNally, A. P.: Operational assimilation of ozonesensitive infrared radiances at ECMWF, Q. J. Roy. Meteor. Soc., doi:10.1002/qj.2106, 2013.

Errico, R. M.: What is an adjoint model?, B. Am. Meteor. Soc., 78, 2577-2591, 1997.

Fischer, H., Birk, M., Blom, C., Carli, B., Carlotti, M., von Clarmann, T., Delbouille, L., Dudhia, A., Ehhalt, D., Endemann, M., Flaud, J. M., Gessner, R., Kleinert, A., Koopman, R., Langen, J., Lopez-Puertas, M., Mosner, P., Nett, H., Oelhaf, H., Perron, G., Remedios, J., Ridolfi, M., Stiller, G., and Zander, R.: MIPAS: an instrument for atmospheric and climate research, Atmos. Chem. Phys., 8, 2151-2188, doi:10.5194/acp-8-2151-2008, 2008.

Flynn, L. E., McNamara, D., Beck, C. T., Petropavlovskikh, I., Beach, E., Pachepsky, Y., Li, Y. P., Deland, M., Huang, L.-K., Long, C. S., Tiruchirapalli, R., and Taylor, S.: Measurements and products from the Solar Backscatter Ultraviolet (SBUV/2) and Ozone Mapping and Profiler Suite (OMPS) instruments, Int. J. Remote Sens., 30, 4259-4272, doi:10.1080/01431160902825040, 2009.

Froidevaux, L., Jiang, Y. B., Lambert, A., Livesey, N. J., Read, W. G., Waters, J. W., Browell, E. V., Hair, J. W., Avery, M. A., Mcgee, T. J., Twigg, L. W., Sumnicht, G. K., Jucks, K. W., Margitan, J. J., Sen, B., Stachnik, R. A., Toon, G. C., Bernath, P. F., Boone, C. D., Walker, K. A., Filipiak, M. J., Harwood, R. S., Fuller, R. A., Manney, G. L., Schwartz, M. J., Daffer, W. H., Drouin, B. J., Cofield, R. E., Cuddy, D. T., Jarnot, R. F., Knosp, B. W., Perun, V. S., Snyder, W. V., Stek, P. C., Thurstans, R. P., and Wagner, P. A.: Validation of Aura Microwave Limb Sounder stratospheric ozone measurements, J. Geophys. Res., 113, D15S20, doi:10.1029/2007JD008771, 2008.

Han, W. and McNally, A. P.: The 4D-Var assimilation of ozonesensitive infrared radiances measured by IASI, Q. J. Roy. Meteor. Soc., 136, 2025-2037, doi:10.1002/Qj.708, 2010.

Hogan, T. F. and Rosmond, T. E.: The description of the Navy Operational Global Atmospheric Prediction System's spectral forecast model, Mon. Weather Rev., 119, 1786-1815, 1991.

Holm, E. V., Untch, A., Simmons, A., Saunders, R., Bouttier, F., and Andersson, E.: Multivariate ozone assimilation in fourdimensional data assimilation, In Proceedings of the SODA Workshop on Chemical Data Assimilation, KNMI, De Bilt, The Netherlands, 9-10 December 1998, 1999.

Lahoz, W. A., Errera, Q., Viscardy, S., and Manney, G. L.: The 2009 stratospheric major warming described from synergistic use of BASCOE water vapour analyses and MLS observations, Atmos. Chem. Phys., 11, 4689-4703, doi:10.5194/acp-11-46892011, 2011.
Levelt, P. F., van den Oord, G. H. J., Dobber, M. R., Mälkki, A., Visser, H., de Vries, J., Stammes, P., Lundell, J., and Saari, H.: The Ozone Monitoring Instrument, IEEE Trans. Geosci. Remote Sens., 44, 1993-1101, doi:10.1109/Tgrs.2006.872333, 2006.

Manney, G. L., Schwartz, M. J., Krüger, K., Santee, M. L., Pawson, S., Lee, J. N., Daffer, W. H., Fuller, R. A., and Livesey, N. J.: Aura Microwave Limb Sounder observations of dynamics and transport during the record-breaking 2009 Arctic stratospheric major warming, Geophys. Res. Lett., 36, L12815, doi:10.1029/2009GL038586, 2009.

Milewski, T. and Bourqui, M. S.: Assimilation of stratospheric temperature and ozone with an ensemble Kalman filter in a chemistry-climate model, Mon. Weather Rev., 139, 3389-3404, doi:10.1175/2011mwr3540.1, 2011.

National Research Council: Earth Science and Applications from Space: National Imperatives for the Next Decade and Beyond, National Academy Press, Washington, DC, 428 pp., available at http://www.nap.edu/catalog.php?record_id=11820, 2007.

Peuch, A., Thepaut, J. N., and Pailleux, J.: Dynamical impact of total-ozone observations in a four-dimensional variational assimilation, Q. J. Roy. Meteor. Soc., 126, 1641-1659, 2000.

Plumb, R. A.: Stratospheric transport, J. Meteor. Soc. Jpn., 80, 793 809, 2002.

Rhines, P. B. and Young, W. R.: How rapidly is a passive scalar mixed within closed streamlines, J. Fluid Mech., 133, 133-145, 1983.

Riishøjgaard, L. P.: On four-dimensional variational assimilation of ozone data in weather-prediction models, Q. J. Roy. Meteor. Soc., 122, 1545-1571, 1996.

Rood, R. B.: Numerical advection algorithms and their role in atmospheric transport and chemistry models, Rev. Geophys., 25, 71-100, 1987.

Rosmond, T. and Xu, L.: Development of NAVDAS-AR: non-linear formulation and outer loop tests, Tellus, 58A, 45-58, 2006.

Salby, M. L. and Juckes, M. N.: An algorithm for retrieving atmospheric motion from satellite measurements of tracer behavior, J. Geophys. Res., 99, 1403-1417, 1994.

Semane, N., Peuch, V.-H., Pradier, S., Desroziers, G., El Amraoui, L., Brousseau, P., Massart, S., Chapnik, B., and Peuch, A.: On the extraction of wind information from the assimilation of ozone profiles in Météo-France 4-D-Var operational NWP suite, Atmos. Chem. Phys., 9, 4855-4867, doi:10.5194/acp-9-4855-2009, 2009.

Stoffelen, A., Pailleux, J., Kallen, E., Vaughan, J. M., Isaksen, L., Flamant, P., Wergen, W., Andersson, E., Schyberg, H., Culoma, A., Meynart, R., Endemann, M., and Ingmann, P.: The atmospheric dynamics mission for global wind field measurement, B. Am. Meteorol. Soc., 86, 73-87, doi:10.1175/Bams-86-1-73, 2005.

Waters, J. W., Read, W. G., Froidevaux, L., Jarnot, R. F., Cofield, R. E., Flower, D. A., Lau, G. K., Pickett, H. M., Santee, M. L., Wu, D. L., Boyles, M. A., Burke, J. R., Lay, R. R., Loo, M. S., Livesey, N. J., Lungu, T. A., Manney, G. L., Nakamura, L. L., Perun, V. S., Ridenoure, B. P., Shippony, Z., Siegel, P. H., and Thurstans, R. P.: The UARS and EOS Microwave Limb Sounder (MLS) experiments, J. Atmos. Sci., 56, 194-218, 1999.

WMO: Statement of guidance regarding how well satellite capabilities meet WMO user requirements in several application areas, WMO Satellite Rep., SAT-22, 29 pp., 2000. 
Xu, L., Rosmond, T., and Daley, R.: Development of NAVDAS-AR: formulation and initial tests of the linear problem, Tellus, 57A, 546-559, 2005.

Žagar, N., Stoffelen, A., Marseille, G. J., Accadia, C., and Schlüssel, P.: Impact assessment of simulated Doppler wind lidars with a multivariate variational assimilation in the tropics, Mon. Weather Rev., 136, 2443-2460, doi:10.1175/2007mwr2335.1, 2008. 